\title{
Service Design Strategy of Public Information Products for Elderly Users
}

\author{
Qin Wang \\ School of Design \\ South China University of Technology \\ Guangzhou, China
}

\begin{abstract}
With the development of urban intelligence, the difficulties the elderly users meet when using public information products attract more attention. While analyzing the characteristics of public information products, the design strategies for elderly users are explored from the perspective of service design, combined with the physiological conditions and cognitive ability of elderly users as well as the universal design principles. Designers should have global awareness, and elderly users and staff users have good use experience. The product follows the principle of universal design, and stakeholders coordinate and cooperate.
\end{abstract}

Keywords-public information products; service design; universal design; elderly users

\section{INTRODUCTION}

With the development of urban intelligence, public information products are increasingly popular. However, due to the operation of the public information products and other factors, the elderly groups have not been fully benefited. Since social participation of the elderly groups contributes to the realization of active aging, the design strategies of public information products for the elderly are explored, which provides a theoretical reference for the design of public information products.

According to the definition of public products and information products by scholars at home and abroad, public information products can be understood as products that provide information use value with sharing, non-competition and non-exclusivity. For example, inquiry machines, ticket buying machines and self-service shopping machines can be used by all members of society in parks, communities, subway stations and supermarkets. Service design is applied to improve user experience and product service [1]. The application of service design to the design of public information products conforms to the characteristics of public products and can effectively solve the design problems in terms of methods.

\section{LITERATURE REVIEW}

There are many researches on public facilities. Li Ying et al. (2019) established evaluation model by quantifying residents' behavior. And the spatial facility distribution was studied by the spatial design method of actively guiding the behavior habits of different groups of people. [2] Zhang Min (2017) analyzed the planning and related policies of New York, London and Tokyo, and the characteristics of the planning orientation, classification system and supply mechanism of public service facilities [3]. Ding Xiong et al. (2016) designed public products and smart tourism services through customer journey optimization, service interface innovation, service touchpoints design and other methods [4]. In terms of human-computer interaction, E Mingshun (2015) analyzed the interface interaction structure and visual elements of electronic products from the perspective of visual physiology and cognition of the elderly [5]. Boll et al. (2015) made a detailed analysis of the specific behaviors and user requirements of the elderly group aged 55 to 75 , and the basic UI design guidelines were obtained [6]. Dodd C et al. (2017) conducted a systematic literature review of the current research regarding user interface development for elderly users over a variety of domains. [7] Chen J\& Or C. (2017) studied the use of an immersive virtual reality, a mouse and a touchscreen by different age groups. Older adults were slower and made more errors in HCI than younger and middle-aged adults. [8]

The existing problems are as follows. First, the number of urban public information products is small, the types are obsolete, and the number of public information products serving the elderly users is insufficient. Second, there are various difficulties for the elderly to use self-service information terminals. Third, the existing public product design is oriented to the mainstream user groups, with little attention paid to the elderly users.

\section{CHARACTERISTICS OF PUBLIC INFORMATION PRODUCTS}

Being non-exclusive, public information products can be consumed or shared by the majority of the society. They are generally provided by government departments to benefit the majority of user groups as much as possible. In terms of design principles, public information products need to reflect the universality, expand the beneficiaries and cover multiple age groups. In terms of the design elements, most of the operation is completed through the touch screen interface, so the human-computer interaction of the display screen is the key point of design. As far as users are concerned, users of different ages differ in computer skills and experience in 
using information technology products. Owing to the deterioration of physical function and cognitive ability, special attention should be paid to the design needs of elderly users.

Public products belong to government public services, and they are usually arranged according to urban space and population density. The existing public facilities are laid out in accordance with the prescribed standard, lacking subjective indicators and feedback on the residents' real life needs. With the popularization of public information products, how to better match users' application of products is highlighted.

\section{ANALYSIS OF ELDERLY USERS}

The characteristics of elderly users are significantly different from ordinary users. The following points are important. Firstly, the physical and physiological functions of elderly users are degraded. They have hyperopia, amblyopia and other eye diseases, so they have special demand for font and color recognition. Secondly, the elderly users' hand strength degenerates and muscle control is weak, so they are slow to press the key and zoom in or out of the screen. Thirdly, the cognitive ability of elderly users deteriorates. Neither can they accurately identify the meaning of the icon nor judge the operation steps of the information interface. Fourthly, the elderly users have information input barriers. Due to the poor education of many elderly people, they are accustomed to handwritten input or oral communication instead of accurate pinyin input text. In addition, some elderly users are frustrated in using information products. Though it is difficult to operate, they are unwilling to ask others for help, and thus gradually resist using information products.

\section{DESIGN PRINCIPLES AND METHODS}

Universal design principles should be adopted for the elderly users. The concept of universal design is proposed by architect Ronald Mace, indicating that design can be used by everyone without any additional assistance. BR Connell et al. put forward seven principles of universal design, including equitable use, flexibility in use, simple and intuitive use, perceptible information, tolerance for error, low physical effort, size and space for approach and use. [9]Public information products should be designed to match the characteristics of elderly users, such as displaying large font, multi-sensory interaction, simplifying steps and button sensitivity.

Service design is an interdisciplinary theory. In the field of design, this concept can be traced back to 1991. Service design is the design of system including stakeholders, touchpoints, services and processes. In the service system, we need to consider the users and providers of services. Service users are elderly users or caregivers. The service provider is civil affairs department or urban planning management department, as well as the producer and designer of public facilities.
The system organization in service design should focus on the customer's experience and pay attention to the user's whole experience. Common user research methods include customer journey map and user experience map. Service blueprint is also adopted to study the entire service system. Service design focuses on the touchpoints of user experience as well as the connection between touchpoints, including how the system operates in the process of connecting the touchpoints.

\section{DESIGN STRATEGY}

Based on the principles of universal design and the methods of service design, various interviews and research data will be collected to design from the use and need of elderly users in the public environment. The following design strategies are proposed for designers, users, products and stakeholders in the service system.

\section{A. Designer}

The designer should manage and plan the whole design process. Designers need to design interfaces and touchpoints. In the service design process, designers focus on the "touchpoints" and the connections between them through the service blueprint. Through collaborative cooperation, leadership and empathy, designers develop information products to help the elderly. Since public facilities include many ancillary services, designers need to conduct a full management of the service system, not only to consider the elderly user experience of the universal design guidelines, but also to focus on the planning and organization of the service providers, as well as the design, use and maintenance of equipment by stakeholders and service terminal. The designer ensures the high quality service of the product system through professional ability and overall awareness.

\section{B. Users}

The service design should consider the experience of the staff and the customer. The elderly users are the terminal users of the device, so we should pay attention to the elderly user experience. The ability of users over 60 years old to access information resources is obviously weak. In order to improve the experience of the elderly users in using public information products, it is necessary to deeply understand the behaviors and needs of the elderly users in the public environment, and analyze the interaction process of customers in the public environment. At the same time, it is also important to consider the user experience of the background staff in the server of the public facilities. They are also users of the service system. They manage the background process of service design, carry out internal coordination and organize to complete a certain work. Improving the user experience of the background staff will help them to create a better experience of products. The staff of the service system shall actively cooperate with the system requirements. In order to ensure the rational use of public information products, staff should check and repair products regularly, actively feedback the problems of elderly users, assist elderly users and ensure the availability of public information products. 
[2] Li Ying, Yan Ting, Zeng Yiyuan, Liu Jiezhen, Zhou Yongjie. Assessment System for Effective Use of Public Service Facilities Based on Quantified Behavior Analysis [J]. Planners, 2019, 35(02): 66-72.

In the system of service design, the product is the terminal device presented to customers. Public information products should provide sufficient information resources for social members, and improve information service and reduce the digital divide. In terms of types, the information products used by the elderly are mainly in the fields of health care, culture and entertainment, transportation, community service, etc. As a touchpoint facing users directly, its design should cater for the cognitive habits and laws of the elderly. An important content of information product design is humancomputer interaction. For example, more attention should be paid to the universality of fonts and icon symbols, simplify the operation steps as far as possible. The input mode of information should be simple and efficient. There are sensory and perceptual deterioration in the elderly, so the interactive mode of visual, auditory and tactile multi-channel is adopted.

\section{Stakeholders}

Stakeholders of public products mainly include government, civil affairs department, data center, product supplier, community staff, participating enterprises, users, etc. The relationship among multiple stakeholders is complex. The effect of public product implementation depends on their mutual cooperation relationships. All stakeholders will affect the number and layout of public facilities, as well as the promotion, use, maintenance, update and recycling of the product life cycle system. The management departments of public information products and their responsibilities should be clear, to ensure the daily management and maintenance of products. It is necessary to provide guidance and publicity on the use of products for the elderly to improve the use rate of products. Service providers and carers need to be patient and pay attention to the use feedback of elderly users.

\section{CONCLUSION}

With the development of smart city, how to effectively serve the growing elderly groups with public information products is an important part of the promotion of urban aging service. Designers, users, products and stakeholders should be concerned in the design strategy research. The designer plans the service process with a global vision. The design of public information products needs universality. The elderly users who use terminal products have special physiological and cognitive characteristics. So the user-friendly humancomputer interface of public information products should be adopted. Stakeholders should coordinate and cooperate to ensure the promotion and maintenance of products and services. Based on the principle of universal design and the method of service design, urban public information products can improve user experience and product service.

\section{REFERENCES}

[1] Zomerdijk L G, Voss C A. Service design for experience-centric services [J]. Journal of Service Research, 2010, 13(1): 67-82. 